\title{
Separation of Am(III), Cm(III), and Cf(III) using capillary electrophoresis
}

\author{
By H. Kikunaga ${ }^{1}$, T. Yoshimura ${ }^{1, *}$, T. Kuribayashi ${ }^{1}$, Y. Kitamoto ${ }^{1}$, N. Takahashi ${ }^{1}$, H. Haba ${ }^{2}$, Y. Ezaki ${ }^{2}$, S. Enomoto ${ }^{2,3}$, \\ T. Mitsugashira ${ }^{4}$ and A. Shinohara ${ }^{1}$ \\ ${ }^{1}$ Department of Chemistry, Graduate School of Science, Osaka University, Toyonaka, Osaka 560-0043, Japan \\ 2 Nishina Center for Accelerator-Based Science, RIKEN, Wako, Saitama 351-0198, Japan \\ ${ }^{3}$ Graduate School of Medicine, Dentistry and Pharmaceutical Science, Okayama University, Tsushima-naka, Okayama 700-8530, Japan \\ ${ }^{4}$ International Research Center for Nuclear Materials Science, Institute for Materials Research, Tohoku University, Oarai, Ibaraki 311-1313, \\ Japan
}

(Received December 20, 2009; accepted in revised form November 12, 2010)

\section{Actinides / Lanthanides / Cesium / Strontium / Capillary electrophoresis}

Summary. Trivalent actinides Am(III), Cm(III), and Cf(III) were successfully separated for the first time using capillary electrophoresis in 2-hydroxyisobutyric acid/acetic acid. It was found that the ionic radius was primarily important for separation of trivalent actinides as well as lanthanides in this condition. The stability constants of the Am(III) complexes with 2-hydroxyisobutyrate were estimated using the correlations between the molar fraction ratio of lanthanides and their ionic radii.

\section{Introduction}

Separation of trivalent actinides and lanthanides is one of the most difficult, because their physical and chemical properties are so similar $[1,2]$. The separation of trivalent actinides and lanthanides is of current interest in the field of the reprocessing of spent nuclear fuel [3-13]. In solution chemistry, ion exchange chromatography and solvent extraction have been well studied for the separation of lanthanides and actinides [3-13]. Capillary electrophoresis (CE) also shows promise for the separation of trivalent actinides because the separation behavior of lanthanides using complex-forming agents is well established for CE [14-17], and the separation of all lanthanides has been accomplished within several minutes $[14,15]$. Several studies on the separation of actinides using CE have been reported [18-21]. Timerbaev applied CE for separation of Th(IV), U(VI), and $\operatorname{Ln}(\mathrm{III})$ [18]. Kuczewski et al. reported separation of $\mathrm{Np}(\mathrm{V}), \mathrm{U}(\mathrm{VI})$, Th(IV), and $\mathrm{La}(\mathrm{III})$. Furthermore they reported separation of $\mathrm{Pu}$ and $\mathrm{Np}$ species with various oxidation states using a CE/ICP-MS system [19]. Separation of $\mathrm{U}(\mathrm{VI}), \mathrm{Np}(\mathrm{V})$, and $\mathrm{Am}(\mathrm{III})$ and that of $\mathrm{Pu}(\mathrm{III}), \mathrm{Pu}(\mathrm{V})$, and $\mathrm{Pu}(\mathrm{VI})$ were demonstrated by Ambard et al. [20]. Recently, separation of $\mathrm{Am}(\mathrm{III})$ from Eu(III) was achieved in an acidic aqueous solution containing thiocyanide by

*Author for correspondence

(E-mail: tyoshi@chem.sci.osaka-u.ac.jp).
Suganuma [21]. However, no study on the mutual separation of trivalent actinides using $\mathrm{CE}$ has been reported. In this study, we report on separation of $\mathrm{Am}(\mathrm{III}), \mathrm{Cm}(\mathrm{III})$, and $\mathrm{Cf}(\mathrm{III})$ using 2-hydroxyisobutyrate $\left(\mathrm{HIB}^{-}\right)$and acetate using CE. Moreover, the separation behaviors of trivalent actinides were compared with those of lanthanides, cesium, and strontium. It was found that the ionic radius was primarily important for separation of trivalent actinides as well as lanthanides. The species of Am(III) and stability constants with $\mathrm{HIB}^{-}$were estimated from the correlation between the ratio of the species of lanthanide in 2-hydroxyisobutyric acid (HIBA)/acetic acid and the ionic radius.

\section{Experimental}

All reagents were analytical grade, unless otherwise specified. Methanol for high-performance liquid chromatography was supplied by Kishida Chemical Co., Ltd. HIBA was supplied by Sigma-Aldrich Co., with a purity of $99 \%$. Creatinine was supplied by Sigma-Aldrich Co. An(III) (Am(III), $\mathrm{Cm}(\mathrm{III})$, and $\mathrm{Cf}(\mathrm{III}))$ tracers were purified as follows. The mixture of $\mathrm{An}(\mathrm{III})$ in $12 \mathrm{~mol} / \mathrm{dm}^{3}$ of $\mathrm{HCl}$ was passed through an anion exchange resin column (Muromac $1 \times 8$ 200-400 mesh). The resin was washed with $12 \mathrm{~mol} / \mathrm{dm}^{3}$ of $\mathrm{HCl}$ to elute $\mathrm{An}$ (III) from the column. This eluate was evaporated to dryness, dissolved in $13.5 \mathrm{~mol} / \mathrm{dm}^{3}$ of $\mathrm{HNO}_{3}$, and then evaporated to dryness. The residue was dissolved in $90 \%$ methanol- $10 \% \mathrm{HNO}_{3}$ solution. The solution was passed through an anion exchange resin column (Muromac $1 \times 8200-400$ mesh) to adsorb An(III). The resin adsorbing An(III) was washed with $90 \%$ methanol- $10 \% \mathrm{HNO}_{3}$ solution. An(III) were eluted from the column with $0.1 \mathrm{~mol} / \mathrm{dm}^{3}$ of $\mathrm{HCl}$. The eluate was evaporated to dryness, and then the residue was dissolved in water; this procedure was repeated for five times. The residue was dissolved in water to adjust to $\mathrm{pH} 3.0$. A radioactive multitracer solution in hydrochloric acid (pH 3) containing ${ }^{85} \mathrm{Sr}$ (II) ${ }^{137} \mathrm{Ce}$ (III), ${ }^{143} \mathrm{Pm}(\mathrm{III}),{ }^{145} \mathrm{Sm}$ (III), ${ }^{146} \mathrm{Eu}(\mathrm{III}),{ }^{153} \mathrm{Gd}(\mathrm{III}),{ }^{88} \mathrm{Y}(\mathrm{III})$, and ${ }^{173} \mathrm{Lu}(\mathrm{III})$, which was prepared by nuclear spallation reaction of ${ }^{197} \mathrm{Au}\left({ }^{14} \mathrm{~N}, X\right)$ at the E3b course of the RIKEN 
Ring Cyclotron, was obtained by separation from the target material like used for purification of $\mathrm{An}(\mathrm{III})$. The $\mathrm{Yb}(\mathrm{III})$ tracer was prepared by the reaction of ${ }^{169} \mathrm{Tm}(p, n)^{169} \mathrm{Yb}$. The product was dissolved in $3 \mathrm{~mol} / \mathrm{dm}^{3}$ of $\mathrm{HNO}_{3}$. The solution was chromatographed on a Ln resin column to separate from the target material. The ${ }^{169} \mathrm{Yb}$ (III) fraction eluted with $8 \mathrm{~mol} / \mathrm{dm}^{3}$ of $\mathrm{HNO}_{3}$ was collected, and then evaporated to dryness. The following purification procedure was almost the same as mentioned above. The ${ }^{137} \mathrm{Cs}(\mathrm{I})$ tracer was used as purchased. The $\mathrm{Am}(\mathrm{III}), \mathrm{Cm}(\mathrm{III}), \mathrm{Cf}(\mathrm{III}), \mathrm{Yb}(\mathrm{III})$, and $\mathrm{Cs}(\mathrm{I})$ tracers were added to the multitracer solution at $\mathrm{pH} 3$.

A fused silica capillary (GL Science) was filled with an electrolyte solution $\left(12 \mathrm{mmol} / \mathrm{dm}^{3}\right.$ of HIBA, $10 \mathrm{mmol} / \mathrm{dm}^{3}$ of creatinine, and varying concentration of acetic acid). The mixture of An(III) tracers in hydrochloric acid ( $\mathrm{pH} 3$ ) was injected into the anode side of the capillary by a hydrostatic method $(10 \mathrm{~cm}$ for $10 \mathrm{~s})$, followed by the electrolyte solution. The electrodes were platinum wires, and a voltage of $+30 \mathrm{kV}$ was applied with Matsusada Precision HCZE $30 \mathrm{PN}$ power supply at room temperature (Fig. 1). The separation behaviors using inactivated capillary (inner diameter $100 \mu \mathrm{m}$ ) were investigated at $\mathrm{pH}=3.10,3.55$, and 3.94 by adjusting the concentration of acetic acid in the electrolyte $\left(0.35 \mathrm{~mol} / \mathrm{dm}^{3}\right.$ at $\mathrm{pH}=3.10,0.087 \mathrm{~mol} / \mathrm{dm}^{3}$ at $\mathrm{pH}=3.55$, and $0.017 \mathrm{~mol} / \mathrm{dm}^{3}$ at $\mathrm{pH}=3.94$ ). At the $\mathrm{pH}=3.10$, the inactivated or untreated silica capillaries with 150,100 , and $75 \mu \mathrm{m}$ inner diameter were also investigated. Separation of trivalent actinides with rare earths, cesium, and strontium in HIBA/acetic acid at $\mathrm{pH}=3.07$ was performed using an inactivated silica capillary $(60 \mathrm{~cm}$ (length) $\times 100 \mu \mathrm{m}$ (i.d.) $)$ with applied voltage $+30 \mathrm{kV}$.

To record the electropherogram, alpha-particle and gamma-ray spectroscopies were used to detect trace amounts of the trivalent actinides, rare earths, strontium, and cesium since detection of radioactivity provides high sensitivity. A tailor-made cartridge covering the capillary at the cathode end was provided to fractionalize the sample solution. The cartridge is composed of a Pt electrode and an electrolyte flowing path to adequately flush the electrophoretically separated samples from the capillary (Fig. 1). In the case of separation of $\mathrm{Am}, \mathrm{Cm}$, and $\mathrm{Cf}$, each drop of electrolyte with a flow rate of $1.2 \mathrm{ml} / \mathrm{min}$ was fractionally collected. In the case of the separation of trivalent actinides, rare earths, strontium, and cesium, the electrolyte with a flow rate of $1.0 \mathrm{ml} / \mathrm{min}$ was fractionally collected at $5 \mathrm{~s}$. The alpha-particle spectrometry was performed with a silicon

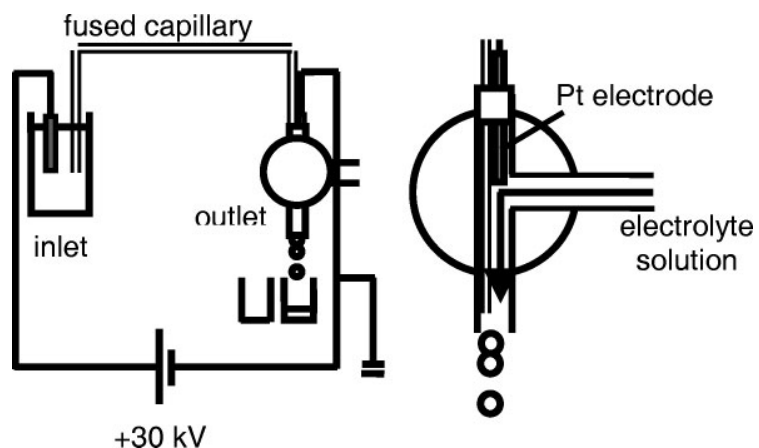

Fig. 1. A schematic of the capillary electrophoresis apparatus (left) and the cartridge attached at the end of the capillary (right). semiconductor detector in vacuo, after the electrolyte solution containing actinides was fractionalized on aluminum plates and was dried by heating. For gamma-ray spectrometry, each fraction was collected into plastic tubes, and the radioactivity was measured using a $\mathrm{Ge}$ semiconductor detector. The electrophoretic mobility was calculated from the peak position of the eluted ion in elapsed time.

\section{Results and discussion}

\subsection{Separation of $\mathrm{Am}, \mathrm{Cm}$, and $\mathrm{Cf}$}

Fig. 2 shows the electropherogram of $\mathrm{An}$ (III) at $\mathrm{pH} 3.10$. The three trivalent actinides were separated in less than 6 min at $+30 \mathrm{kV}$, and moved in order of the atomic number; Am(III) eluted first, followed by $\mathrm{Cm}$ (III), and then $\mathrm{Cf}(\mathrm{III})$. This order was also observed both at $\mathrm{pH} 3.55$ and 3.90. The degree of separation of $\mathrm{Am}$ (III) and $\mathrm{Cm}$ (III) decreased with increasing electrolyte $\mathrm{pH}$, since pronounced tailing appears as $\mathrm{pH}$ and acetate concentration of the electrolyte increase. At $\mathrm{pH} 3.10$, the peak positions of $\mathrm{Am}$ (III) and $\mathrm{Cm}$ (III) were well resolved and $\mathrm{Cf}(\mathrm{III})$ was separated completely from $\mathrm{Am}(\mathrm{III})$ and $\mathrm{Cm}(\mathrm{III})$. At $\mathrm{pH} 3.10$, separation of Am(III), $\mathrm{Cm}$ (III), and $\mathrm{Cf}(\mathrm{III})$ was performed using three types of capillaries 75,100 , and $150 \mu \mathrm{m}$ in inner diameter. The separation of $\mathrm{Am}(\mathrm{III}), \mathrm{Cm}(\mathrm{III})$, and $\mathrm{Cf}(\mathrm{III})$ using $150 \mu \mathrm{m}$ of the capillary was lesser compared with those using 75 and $100 \mu \mathrm{m}$.

\subsection{Separation of trivalent actinide, lanthanide, strontium, and cesium}

Table 1 shows the electrophoretic mobility of actinides, rare earths, strontium, and cesium ions. In the separation, cesium ions were eluted at first, followed by strontium, and then lanthanides and trivalent actinides. The lanthanides were eluted in the order of the atomic number as reported in the literature [14]. Am(III), Cm(III), and Cf(III) was eluted within the range of the rare earths. The mobility values of Am(III) and $\mathrm{Cm}$ (III) were between that of Pm(III) and Sm(III), and these

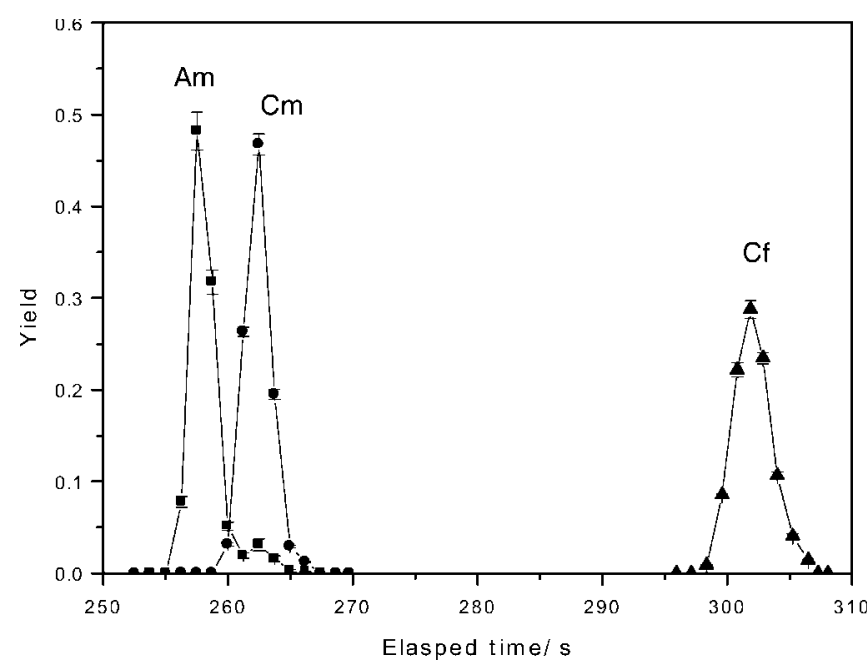

Fig. 2. Electropherogram of $\mathrm{Am}(\mathrm{III}), \mathrm{Cm}(\mathrm{III})$, and $\mathrm{Cf}(\mathrm{III})$ in HIBA $\left(12 \mathrm{mmol} / \mathrm{dm}^{3}\right) /$ acetic acid at $\mathrm{pH} 3.10$ (Am: filled square, Cm: filled circle, Cf: filled triangle). The applied voltage is $+30 \mathrm{kV}$. 
Table 1. Electrophoretic mobility values of trivalent actinides, lanthanides, strontium, and cesium in HIBA $\left(12 \mathrm{mmol} / \mathrm{dm}^{3}\right) /$ acetic acid at $\mathrm{pH} 3.07$.

\begin{tabular}{lcc}
\hline Metal ion & $\begin{array}{c}\text { Electrophoretic mobility } \times 10^{5} / \mathrm{cm}^{2} \mathrm{~V}^{-1} \mathrm{~s}^{-1} \\
\text { Experimental }\end{array}$ & Simulated \\
\hline Am(III) & $44.0 \pm 0.8$ & \\
Cm(III) & $43.2 \pm 0.8$ & \\
Cf(III) & $37.8 \pm 0.6$ & \\
Cs(I) & $94.0 \pm 3.7$ & \\
Sr(II) & $67.5 \pm 1.9$ & \\
Y(III) & $38.4 \pm 0.6$ & 51.2 \\
La(III) & & 47.9 \\
Ce(III) & $49.6 \pm 1.0$ & 46.5 \\
Pr(III) & & 45.4 \\
Nd(III) & & \\
Pm(III) & $44.4 \pm 0.8$ & 42.8 \\
Sm(III) & $42.6 \pm 0.8$ & 41.9 \\
Eu(III) & $41.7 \pm 0.7$ & 41.4 \\
Gd(III) & $41.2 \pm 0.7$ & 39.4 \\
Tb(III) & & 38.0 \\
Dy(III) & & 37.0 \\
Ho(III) & & 35.9 \\
Er(III) & & 34.6 \\
Tm(III) & & 33.4 \\
Yb(III) & & 32.6 \\
Lu(III) & & \\
\hline & $29.4 \pm 0.4$ &
\end{tabular}

values were so larger than those of $4 \mathrm{f}$ congeners $\mathrm{Eu}(\mathrm{III})$ and $\mathrm{Gd}(\mathrm{III})$. The mobility value of $\mathrm{Cf}(\mathrm{III})$ was smaller than that of Gd(III) and similar to that of Y(III). The mobility of lanthanides decreases with decreasing its ionic radius. This is attributed to the difference of effective charge by formation of the metal complex with $\mathrm{HIB}^{-}$and acetate, since the stability constant of the complex with $\mathrm{HIB}^{-}$/acetate increases with decreasing the ionic radius of the metal ion [22-26]. These results suggest that the main contribution to separation of the trivalent actinides under these conditions is the difference of the ionic radius of the metal ion, which affects the stability constants and molar fraction of the complexes existing in the electrolyte. In our experiment, $\mathrm{Cs}(\mathrm{I})$ and $\mathrm{Sr}(\mathrm{II})$ were eluted faster than trivalent lanthanide and

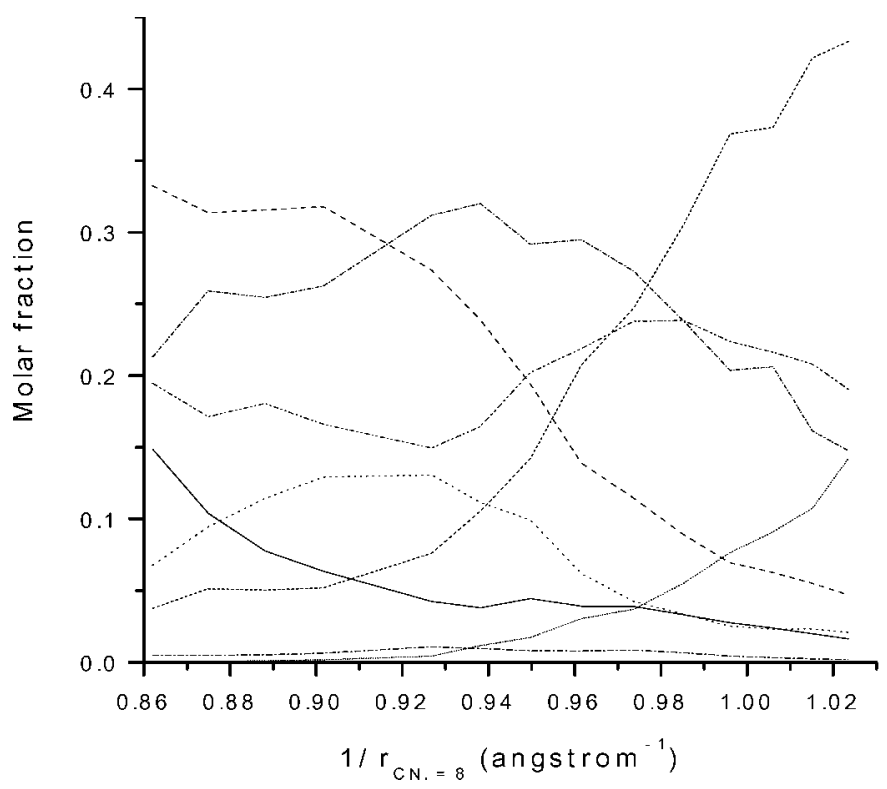

actinides. The trend that alkali metal and alkali-earth metal ions showed larger mobility than lanthanides is consistent with the results in the literature [15]. The smaller charge and larger ionic radius of $\mathrm{Cs}(\mathrm{I})$ and $\mathrm{Sr}(\mathrm{II})$ as compared to trivalent lanthanides and actinides may result in the larger effective charge by formation of the metal complex with $\mathrm{HIB}^{-}$and acetate.

\subsection{Speciation of Am(III) in HIBA/acetic acid}

We discuss at first about the relation between the separation behavior of trivalent actinides and lanthanide and the eightor six-coordination ionic radius. The six-coordinate ionic radius decreases in the order $A m(0.975 \AA)>\operatorname{Pm}(0.97 \AA)=$ $\mathrm{Cm}(0.97 \AA)>\mathrm{Sm}(0.958 \AA)$ [27]. On the other hand, the eight-coordinate ionic radius is decreased in the order Pm $(1.093 \AA)>\operatorname{Am}(1.09 \AA)>\operatorname{Sm}(1.079 \AA)$ [27]. The eightcoordinate ionic radius of $\mathrm{Cm}(\mathrm{III})$ and nine-coordinate ionic radii of $\mathrm{Am}(\mathrm{III})$ and $\mathrm{Cm}(\mathrm{III})$ are not determined [27]. The mobility value of our results in electrophoresis decreased in the order $\mathrm{Pm}>\mathrm{Am}>\mathrm{Cm}>\mathrm{Sm}$. Accordingly, a trend for the order of the mobility values is in good agreement with the order of the values of the eight-coordinate ionic radius. In the single-crystal X-ray study of the lanthanide complexes with $\mathrm{HIB}^{-}$, the lanthanide atoms are eight-coordinate structures [28]. It is premature to conclude that the complex in the present experimental condition is eight-coordinate structure, since in the case of the $\mathrm{Cm}$ (III) complexes with glycolate, the estimated coordination numbers of $\mathrm{Cm}$ (III) is between 8 and 9 [29].

Hirokawa et al. reported the information on the mobility of lanthanides using isotachophoresis and stability constants of the individual complexes having $\mathrm{HIB}^{-}$and acetate [30]. We applied for the method to derive stability constants of the complexes for $\mathrm{Am}(\mathrm{III})$ with $\mathrm{HIB}^{-}$. At first, the ratio of the eight lanthanide complexes $\left[\operatorname{Ln}(\mathrm{HIB})_{3}\right],\left[\operatorname{Ln}(\text { acetate })_{3}\right]$, $\left[\operatorname{Ln}(\mathrm{HIB})_{2}\right]^{+}, \quad[\operatorname{Ln}(\mathrm{HIB})(\text { acetate })]^{+}, \quad\left[\operatorname{Ln}(\text { acetate })_{2}\right]^{+}$, $[\mathrm{Ln}(\mathrm{HIB})]^{2+},[\operatorname{Ln}(\text { acetate })]^{2+}$, and $[\mathrm{Ln}]^{3+}$ was calculated along with our experimental condition $(\mathrm{pH}$ 3.07) using the parameters reported in the literature [30]. Fig. 3 shows the

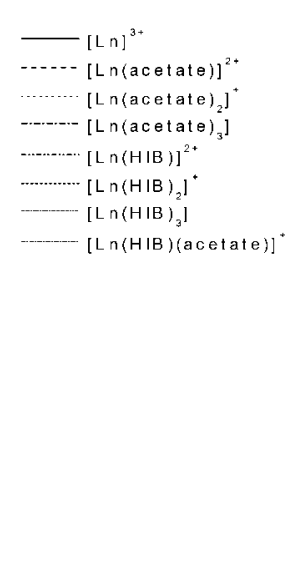

Fig. 3. The molar fraction of lanthanide complexes vs. reciprocal ionic radius of lantanide ion $(\mathrm{CN}=8)$ in HIBA $\left(12 \mathrm{mmol} / \mathrm{dm}^{3}\right) /$ acetic acid at $\mathrm{pH} 3.07$. 


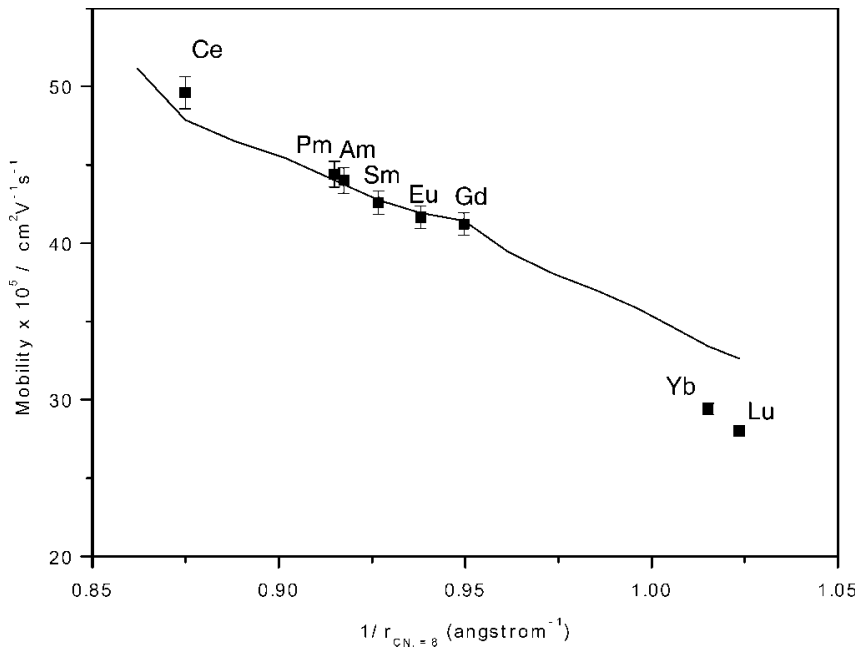

Fig. 4. The plot of electrophoretic mobility against reciprocal ionic radius $(\mathrm{CN}=8)$. The solid line is simulated electrophoretic mobility.

Table 2. Calculated stability constants of $\mathrm{Am}(\mathrm{III})$ and $\mathrm{Pm}(\mathrm{III})$ complexes, respectively, with $\mathrm{HIB}^{-}$.

\begin{tabular}{llcc}
\hline & $\log \beta_{1}$ & $\log \beta_{2}$ & $\log \beta_{3}$ \\
\hline $\operatorname{Am}($ III) & 3.36 & 5.87 & 7.46 \\
$\operatorname{Pm}($ III $)$ & 3.35 & 5.84 & 7.41 \\
\hline
\end{tabular}

ratio of each complex vs. reciprocal ionic radius of eight coordinate trivalent lanthanides. Fig. 4 exhibits the observed and simulated electrophoretic mobilities of lanthanides together with the observed mobility values of Am(III) and Pm(III). The simulated mobility for each lanthanide includes a constant value $\left(9.466 \mathrm{~cm}^{2} \mathrm{~V}^{-1} \mathrm{~s}^{-1}\right)$, which relate to electroosmotic flow, as the simulated line is in good agreement with the data points of the observed mobility values of lanthanides. It should be noted that the mobility value of Am(III) lies on the simulated line for those of lanthanides. Therefore, we suppose that the molar fraction ratio and stability constant of the Am(III) complex is calculated by interpolation of the plot of molar fraction of the $\mathrm{Nd}(\mathrm{III})$ and $\mathrm{Sm}$ (III) complexes against reciprocal ionic radius. Table 2 showed that the calculated stability constants of the Am(III) and $\mathrm{Pm}$ (III) complexes, respectively, with $\mathrm{HIB}^{-}$. The values of calculated stability constants are quite reasonable as compared to the trend that the stability constants of Am(III) and Pm(III) in the literature are similar [27].

Acknowledgment. The present study includes the results of the efficient separation and analysis of nuclear fission products for reprocessing systems entrusted to Osaka University by the Ministry of Education, Culture, Sports, Science and Technology of Japan (MEXT).

\section{References}

1. Cotton, S.: Lanthanide and Actinide Chemistry. Wiley, Weinheim (2006), p. 149.

2. Morss, L. R., Edelstein, N. M., Fuger, J.: The Chemistry of the Actinide and Transactinide Elements. $3^{\text {rd }}$ Edn., Springer, Dordrecht (2006), Vol. 3, Chapt. 15, p. 1753.

3. Choppin, G. R., Morgenstern, A.: Radionuclide separations in radioactive waste disposal. J. Radioanal. Nucl. Chem. 243, 45 (2000) and references therein.
4. Suzuki, T., Fujii, Y., Koyama, S., Ozawa, M.: Nuclide separation from spent nuclear fuels by using tetiary pyridine resin. Prog. Nucl. Energy 50, 456 (2008) and references therein.

5. Suzuki, T., Ohtake, K., Sato, M., Ikeda, A., Aida, M., Fujii, Y., Hara, M., Mitsugashira, T., Ozawa, M.: Separation of americium and curium by use of tertiary pyridine resin in nitric acid/methanol mixed solvent system. J. Radioanal. Nucl. Chem. 272, 257 (2007).

6. Ikeda, A., Suzuki, T., Aida, M., Fujii, Y., Itoh, K. Mitsugashira, T., Hara, M., Ozawa, M.: Effect of alcohols on elution chromatography of trivalent actinides and lanthanides using tertiary pyridine resin with hydrochloric acid-alcohol mixed solvents. J. Chromatogr. A 1041, 195 (2004).

7. Arisaka, M., Kimura, T., Suganuma, H., Yoshida, Z.: Direct evidence for enhanced inner-sphere chloro complexation of Eu(III) and $\mathrm{Cm}(\mathrm{III})$ in anion exchange resin phase studied by timeresolved laser-induced fluorescence spectroscopy. Radiochim. Acta 90, 193 (2002).

8. Ekberg, C., Fermvik, A., Retegan, T., Skarnemark, G., Foreman, M. R. S., Hudson, M. J., Englund, S., Nilsson, M.: An overview and historical look back at the solvent extraction using nitrogen donor ligands to extract and separate An(III) from Ln(III). Radiochim. Acta 96, 225 (2008) and references therein.

9. Sasaki, Y., Kimura, T., Oguma, K.: Solvent extraction of various metals including actinides by bidentate and tridentate diamides. J. Ion Exchange 18, 354 (2007).

10. Ishimori, K., Watanabe, M., Yaita, T., Kimura, T., Yamada, T., Shinoda, S., Tsukube, H.: Synergistic extraction of Am(III) and $\mathrm{Eu}(\mathrm{III})$ by tris(2-pyridylmethyl)amine with various anions in 1,2dichloroethane. Chem. Lett. 630 (2009).

11. Ishimori, K., Watanabe, M., Kimura, T., Yaita, T., Yamada, T., Kataoka, Y., Shinoda, S., Tsukube, H.: Novel separation system of trivalent actinides-combined effects of substituted tris(2pyridylmethyl)amine ligand and hydrophobic counter-anion. Chem. Lett. 1112 (2005).

12. Naganawa, H., Suzuki, H., Noro, J., Kimura, T.: Selective separation of Am(III) from lanthanides(III) by solvent extraction with hydrophobic field of "superweak" anion. Chem. Commun. 2963 (2005).

13. Sasaki, Y., Choppin, G. R.: Extraction and mutual separation of actinide(III), (IV), (V), and (VI) ions by $N, N^{\prime}$-dimethyl$N, N^{\prime}$-dihexyl-3-oxapentanediamine and thenoyltrifluoroacetone. J. Nucl. Radioanal. Nucl. Chem. 246, 267 (2000).

14. Janoš, P.: Analytical separations of lanthanides and actinides by capillary electrophoresis. Electrophoresis 24, 1982 (2003).

15. Shi, Y., Fritz, J. S.: Separation of metal ions by capillary electrophoresis with a complexing electrolyte. J. Chromatogr. 640, 473 (1993).

16. Day, J. A., Caruso, J. A., Becker, J. S., Dietze, H.-J.: Application of capillary electrophoresis interfaced to double focusing sector field ICP-MS for nuclide abundance determination of lanthanides produced via spallation reactions in an irradiated tantalum target. J. Anal. At. Spectrom. 15, 1343 (2000).

17. Kautenburger, R., Beck, H. P.: Complexation studies with lanthanides and humic acid analyzed by ultrafiltration and capillary electrophoresis-inductively coupled plasma mass spectrometry. J. Chromatogr. A 1159, 75 (2007).

18. Timerbaev, A. R.: Recent advances and trends in capillary electrophoresis of inorganic ions. Electrophoresis 23, 3884 (2002).

19. Kuczewski, B., Marquardt, C. M., Seibert, A., Geckeis, H., Kratz, J. V., Trautmann, N.: Separation of plutonium and neptunium species by capillary electrophoresis-inductively coupled plasmamass spectrometry and application to natural groundwater samples. Anal. Chem. 75, 6769 (2003).

20. Ambard, C., Delorme, A., Baglan, N., Aupiais, J., Pointurier, F., Madic, C.: Interfacing capillary electrophoresis with inductively coupled plasma mass spectrometry forredox speciation of plutonium. Radiochim. Acta 93, 665 (2005).

21. Mori, T., Ishii, Y., Hayashi, K., Yanaga, M., Satoh, I., Suganuma, H.: Separation of $\mathrm{Am}^{\mathrm{III}}$ from $\mathrm{Eu}^{\mathrm{III}}$ using an improved system of flow-counterbalanced capillary electrophoresis. Chem. Lett. 48 (2008). 
22. Choppin, G. R., Chopoorian, J. A.: Complexes of the lanthanide elements with $\alpha$-hydroxy carboxylate ligands. J. Inorg. Nucl. Chem. 22, 97 (1961).

23. Stagg, W. R., Powell, J. E.: Complexes of the trivalent rare earths with isobutyrate, $\alpha$-hydroxyisobutyrate, and $\alpha, \beta, \beta^{\prime}$ trihydroxyisobutyrate ligands. Inorg. Chem. 3, 242 (1964).

24. Deelstra, H., Verbeek, F.: The determination of the stability constants of the lanthanide $\alpha$-hydroxyisobutyrate and lactate complexes by potentiometric titration. Anal. Chim. Acta 31, 251 (1964).

25. Stary, J.: Separation of transplutonium elements. Talanta 13, 421 (1966).
26. Shalinets, A. B.: Complexing of trivalent actinide and lanthanide elements studied by electromigration. XI. Stability of complexes to strong acid. Radiokhimiya 13, 566 (1971).

27. Shannon, R. D.: Revised effective ionic radii and systematic studies of interatomic distances in halide and chalcogenides. Acta Cryst. A 32, 751 (1976).

28. Yoshimura, T., Kikunaga, H., Shinohara, A.: to be submitted.

29. Stumpf, T., Fanghänel, T., Grenthe, I.: Complexation of trivalent actinide and lanthanide ions by glycolic acid: a TRLFS study. J. Chem. Soc. Dalton Trans. 3799 (2002).

30. Hirokawa, T., Aoki, N., Kiso, Y.: Complex-forming equilibria in isotachophoresis. J. Chromatogr. 312, 11 (1984). 